\title{
An Audit on Management of G6PD Deficiency Acute Hemolytic Crisis
} Alaa Mohammed Abd El-Aty*, Safiea Abd El-Fattah El-Deeb and Mostafa Mohamed Embaby

Department of Pediatrics, Faculty of Medicine, Assiut University, Egypt

\begin{abstract}
Introduction: Hemolytic anemia is a common cause of anemia in our country. It may results from a cellular defect that changes the shape of RBCs from biconcave to spherical as in spherocytosis or elliptical as in elliptocytosis. It may results from RBCs enzyme deficiency as in cases with pyruvate kinase deficiency or glucose-6-phosphate dehydrogenase enzyme deficiency (G6PD deficiency). Other causes of hemolytic anemia include hemoglobinopathy, autoimmune antibodies against RBCs, hypersplenism and others.
\end{abstract}

G6PD deficiency is the most important disease of the hexose monophosphate pathway and is responsible for two clinical syndromes, an episodic hemolytic anemia induced by infections, certain drugs or fava beans and a spontaneous chronic non spherocytic hemolytic anemia.

G6PD deficiency is an inherited disorder caused by a genetic defect in the RBCs enzyme G6PD, which generates NADPH and protects RBCs from oxidative injury. G6PD deficiency is the most common enzymatic disorder of RBCs. Although G6PD is a critical enzyme in the redox metabolism of all aerobic cells, yet its role in the RBCs is more critical because it is the only source of NADPH which directly and via GSH defends these cells against oxidative stress. G6PD deficiency is an example of hemolytic anemia due to interaction between an intra-corpuscular cause and an extra corpuscular cause, because in the majority of cases hemolysis is triggered by an exogenous agent. The severity of hemolytic anemia varies among individuals with G6PD deficiency. Education of patients and their parents regarding safe and unsafe medications and foods is crucial to prevent future episodes of hemolysis. In many cases all members of the patient's family should avoid such precipitating foods. G6PD deficiency is a sex-linked disorder. As result males who inherit a G6PD mutation are hemizygous for the defect all their RBCs are affected. Females who inherit a heterozygous G6PD mutation usually do not have severe hemolytic anemia, since half of their RBCs express the abnormal allele. The majority of females who inherit an abnormality in G6PD are unaffected carriers. However, the cells that express the abnormal allele are vulnerable to hemolysis as the enzyme deficient RBCs in males. The presence of anemia will vary depending on the severity of the deficiency in the affected cells and whether there is skewed x-inactivation (lyonization) that results in a greater expression in a large percentage of RBCs. G6PD deficiency is a common genetic disorder, affecting nearly 400 million individuals worldwide. Whilst it is known that a number of drugs, foods and chemicals can trigger hemolysis in G6PD deficient individuals, the association between herbal and dietary supplements and hemolysis is less clear. Amongest nutrients blamed as triggers for hemolysis in G6PD deficient individuals are fava beans and related ligaments. Oxidant drugs and infections also predispose to hemolytic attacks. Provided that the blood of a G6P deficient person is normal, acute hemolysis results from the action of an exogenous factor on the RBCs deficient in glucose-6-phosphate dedydrogenase (G6PD). The function of G6PD in RBCs is to provide the reduced form of nicotinamide adenine dinucleotide phosphate (NADPH) necessary for the conversion of oxidized glutathione to the reduced state $(\mathrm{GSH})$ as protection against the oxidation of RBCs. So that reduced glutathione (GSH) acts as an anti-oxidant that inactivates oxidant compounds such as hydrogen peroxide, that are normally generated within the RBCs. If GSH or any enzyme needed for maintaining glutathione in the reduced form (GSH) is deficient, the SH group in the RBCs membrane is oxidized and the hemoglobin of the RBCs is denatured and may precipitate in the RBC inclusions called Heinz bodies. An acute hemolytic process (crisis) results from damage to the RBC membrane by precipitated hemoglobin induced by the exogenous oxidant agent. The damaged RBCs are rapidly removed from the circulation causing acute drop in $\mathrm{Hb}$ level and the acute hemolytic crisis. This episodic acute hemolytic anemia may be induced by infections, certain drugs and fava beans. Glucose-6-phosphate dedydrogenase (G6PD) deficiency is inherited in an $x$-linked manner, so that the synthesis of RBCs G6PD is determined by a gene on x-chromosome. Thus most females do not usually have evident clinical hemolysis after exposure to oxidant agents, unless new gene mutation has occurred. In Egypt ingestion of fava beans produces an acute severe hemolytic crisis known as favism. Fava beans contain divicine, isouramil and convicine which ultimately lead to production of hydrogen peroxide and other reactive oxygen species production. Therefore, seasonal increased prevalence of G6PD deficiency crisis occurs in the green beans growth season. This is usually manifested by drop in $\mathrm{Hb}$, hemoglobinuria, hyperbilirubinemia and reticulocytosis. These patients usually have to be rescued by packed RBCs transfusion. The list of drugs to be avoided in G6PD deficient individuals (whether causing predictable or possible hemolysis) must be given to all cases that present in crisis.

The aim of the study: To find out how much the staff in the Emergency unit are sticking to the agreed upon unit's protocol as well as to compare the unit's protocol with European Guidelines.

Subjects: Children from 1 day to 18 years of age with G6PD acute hemolytic crisis attending Assiut University Children Hospital over one year 2015-2016.

Inclusion criteria: All cases of G6PD deficiency acute hemolytic crisis

Tools of study: The investigations stated in the unit's protocol included CBCs, urine dipsticks, blood urea and 
creatinine, serum bilirubin (direct and indirect) as well as blood grouping and cross matching. After treatment of the crisis (as stated in the unit's protocol) a list of drugs and agents to be avoided was given to the patients. The patients were advised to return to follow up after four weeks for the measurement of G6PD enzyme level in the outpatient department in Assiut university children Hospital.

Patients and methods: This study was performed in the Emergency Unit in Assiut University Children Hospital for one year 2015-2016 (Nov, 2015 to Nov, 2016). The study included fifty cases of acute G6PD hemolytic crisis admitted to the emergency unit: they were aged nine months to four years. They were 45 males and 5 females. The investigations stated in the unit's protocol included CBCs, urine dipsticks, blood urea and creatinine, serum bilirubin (direct and indirect) as well as blood grouping and cross matching. After treatment of the crisis (as stated in the unit's protocol) a list of drugs and agents to be avoided was given to the patients. The patients were advised to return to follow up after four weeks for the measurement of G6PD enzyme level in the outpatient department in Assiut university children Hospital.

Results: The study included fifty cases of acute G6PD hemolytic crisis admitted to the emergency unit: they were aged nine months to four years. They were 45 males and 5 females.

Keywords: Glucose-6-phosphate dehydrogenase enzyme deficiency (G6PD deficiency); Hemolytic anemia; Fava beans; Haemoglobinopathy; Reticulocytosis

Abbreviations: G6PD: Glucose-6-Phosphate Dehydrogenase Enzyme Deficiency; RBCs: Red Blood Cells; NADPH: Nicotinamide Adenine Dinucleotide Phosphate

\section{Introduction}

Hemolytic anemia is a common cause of anemia in our country. It may results from a cellular defect that changes the shape of RBCs from biconcave to spherical as in spherocytosis or elliptical as in elliptocytosis. It may results from RBCs enzyme deficiency as in cases with pyruvate kinase deficiency or glucose-6-phosphate dehydrogenase enzyme deficiency (G6PD deficiency). Other causes of hemolytic anemia include hemoglobinopathy, autoimmune antibodies against RBCs, hypersplenism and others. G6PD deficiency is the most important disease of the hexose monophosphate pathway and is responsible for two clinical syndromes, an episodic hemolytic anemia induced by infections, certain drugs or fava beans and a spontaneous chronic non spherocytic hemolytic anemia. G6PD deficiency is an inherited disorder caused by a genetic defect in the RBCs enzyme G6PD, which generates NADPH and protects RBCs from oxidative injury. G6PD deficiency is the most common enzymatic disorder of RBCs. Although G6PD is a critical enzyme in the redox metabolism of all aerobic cells, yet its role in the RBCs is more critical because it is the only source of NADPH which directly and via GSH defends these cells against oxidative stress. G6PD deficiency is an example of hemolytic anemia due to interaction between an intra-corpuscular cause and an extra corpuscular cause, because in the majority of cases hemolysis is triggered by an exogenous agent [1-8]. The severity of hemolytic anemia varies among individuals with G6PD deficiency. Education of patients and their parents regarding safe and unsafe medications and foods is crucial to prevent future episodes of hemolysis. In many cases all members of the patient's family should avoid such precipitating foods. G6PD deficiency is a sex-linked disorder. As result males who inherit a G6PD mutation are hemizygous for the defect all their RBCs are affected. Females who inherit a heterozygous G6PD mutation usually do not have severe hemolytic anemia, since half of their RBCs express the abnormal allele. The majority of females who inherit an abnormality in G6PD are unaffected carriers. However, the cells that express the abnormal allele are vulnerable to hemolysis as the enzyme deficient RBCs in males. The presence of anemia will vary depending on the severity of the deficiency in the affected cells and whether there is skewed $\mathrm{x}$-inactivation (lyonization) that results in a greater expression in a large percentage of RBCs [5]. G6PD deficiency is a common genetic disorder, affecting nearly 400 million individuals worldwide. Whilst it is known that a number of drugs, foods and chemicals can trigger hemolysis in G6PD deficient individuals, the association between herbal and dietary supplements and hemolysis is less clear [6]. Amongest nutrients blamed as triggers for hemolysis in G6PD deficient individuals are fava beans and related leguments. Oxidant drugs and infections also predispose to hemolytic attacks. Provided that the blood of a G6P deficient person is normal, acute hemolysis results from the action of an exogenous factor on the RBCs deficient in glucose-6-phosphate dedydrogenase (G6PD). The function of G6PD in RBCs is to provide the reduced form of nicotinamide adenine dinucleotide phosphate (NADPH) necessary for the conversion of oxidized glutathione to the reduced state (GSH) as protection against the oxidation of RBCs. So that reduced glutathione (GSH) acts as an anti-oxidant that inactivates oxidant compounds such as hydrogen peroxide, that are normally generated within the RBCs. If GSH or any enzyme needed for maintaining glutathione in the reduced form (GSH) is deficient, the SH group in the RBC's membrane is oxidized and the hemoglobin of the RBCs is denatured and may precipitate in the RBC inclusions called Heinz bodies. An acute hemolytic process (crisis) results from damage to the RBC membrane by precipitated hemoglobin induced by the exogenous oxidant agent. The damaged RBCs are rapidly removed from the circulation causing acute drop in $\mathrm{Hb}$ level and the acute hemolytic crisis. This episodic acute hemolytic anemia may be induced by infections, certain drugs and fava beans. Glucose-6-phosphate dedydrogenase (G6PD) deficiency is inherited in an x-linked manner, so that the synthesis of RBCs G6PD is determined by a gene on $\mathrm{x}$-chromosome. Thus most females do not usually have evident clinical hemolysis after exposure to oxidant agents, unless new gene mutation has occurred. In Egypt ingestion of fava beans produces an acute severe hemolytic crisis known as favism. Fava beans contain

*Corresponding author: El-Aty AMA, Department of Pediatrics, Faculty of Medicine, Assiut University, Egypt, Tel: +201017159694; E-mail: digaalaa@yahoo.com

Received October 11, 2017; Accepted October 31, 2017; Published November 15,2017

Citation: El-Aty AMA, El-Deeb SAEF, Embaby MM (2017) An Audit on Management of G6PD Deficiency Acute Hemolytic Crisis. J Blood Lymph 7: 186 doi: 10.4172/2165-7831.1000186

Copyright: (c) 2017 El-Aty AMA, et al. This is an open-access article distributed under the terms of the Creative Commons Attribution License, which permits unrestricted use, distribution, and reproduction in any medium, provided the original author and source are credited. 
divicine, isouramil and convicine which ultimately lead to production of hydrogen peroxide and other reactive oxygen species production. Therefore, seasonal increased prevalence of G6PD deficiency crisis occurs in the green beans growth season. This is usually manifested by drop in $\mathrm{Hb}$, hemoglobinuria, hyperbilirubinemia and reticulocytosis. These patients usually have to be rescued by packed RBCs transfusion. The list of drugs to be avoided in G6PD deficient individuals (whether causing predictable or possible hemolysis) must be given to all cases that present in crisis (Figures 1-5).

\section{Discussion}

It is interesting to find that our cases with acute hemolytic crisis stated at age of nine months, where weaning foods with split peas and fava beans are introduced. In fact $32 \%$ of our cases were aged between nine and eighteen months. In $90 \%$ of our cases male sex was encountered but female children constituted $10 \%$ of cases, which are probably severe hemizygous in nature. Regarding the use of urine dipsticks for the diagnosis of presence of hemoglobinuria in cases of acute hemolytic crisis, although it was done in $80 \%$ of cases, yet it was not done in $20 \%$ of cases. So that unit's protocol was followed in $80 \%$ of cases. Regarding the measurement of serum bilirubin: it was not done in $46 \%$ of cases. This is to say that the unit's protocol regarding this point was only

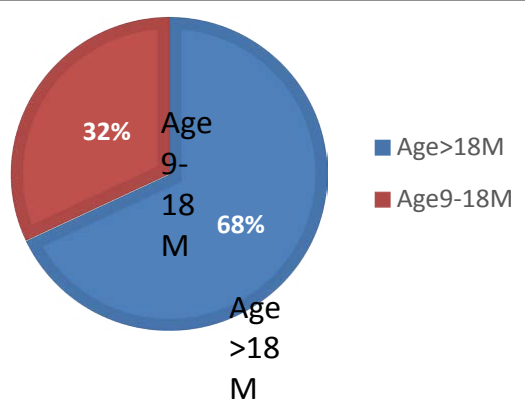

Figure 1: The age distribution of cases with acute hemolytic crisis.

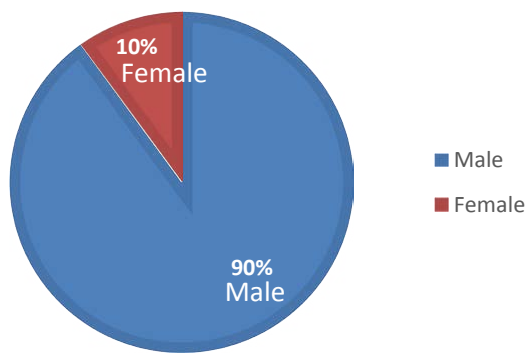

Figure 2: The sex distribution of cases with acute hemolytic crisis.

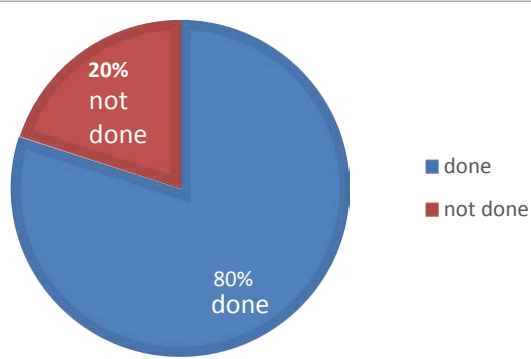

Figure 3: The percentage of cases where urine dipsticks were done.

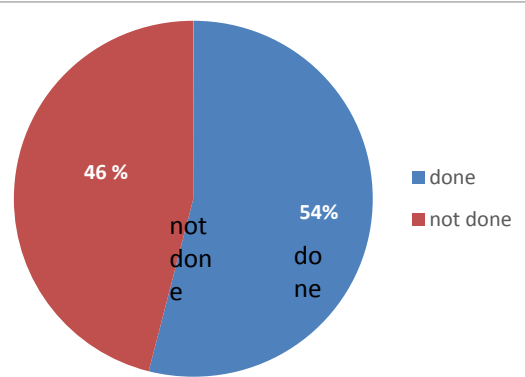

Figure 4: The percentage of cases where serum bilirubin was measure.

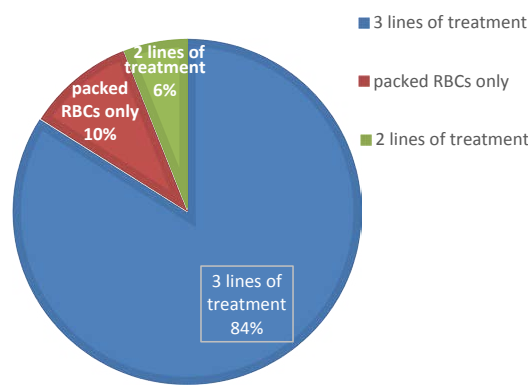

Figure 5: The percentage where one line of treatment (packed RBCs only was used in $10 \%$ of cases), two lines of treatment (packed RBCs+maintenance intravenous fluids were given in $6 \%$ of cases). The three lines of treatment namely packed RBCs, maintenance intravenous fluids and sodium bicarbonate were given in $84 \%$ of cases.

followed in 54\% of cases. Regarding the lines of treatment stated in the unit's protocol it was recommended that three lines of treatment to be used in all cases (namely packed RBCs, maintenance intravenous fluids, sodium bicarbonate). This was followed in $84 \%$ of cases. In $6 \%$ of cases two lines of treatment were used (packed RBCs+maintenance intravenous fluids). In $10 \%$ of cases only one line of treatment (packed RBCs) was given. Table 1 shows the practicability of sticking to the unit's protocol.

It was observed that $\mathrm{CBCs}$ with reticulocytic count was done in $100 \%$ of the cases

- Urine dipsticks were done in $80 \%$ of the cases.

- Blood urea and creatinine were done in $100 \%$ of the cases.

- Serum bilirubin (direct and indirect) was done in $54 \%$ of the cases.

- Blood group and cross matching were done in $100 \%$ of the cases.

- Blood transfusion with packed RBCs only was done in $10 \%$ of the cases.

- Packed RBCs transfusion+maintenance intravenous fluids were done in $6 \%$ of the cases. While in $84 \%$ of the cases packed RBCs transfusion+maintenance intravenous fluids+sodium bicarbonate were done.

- Observation of the patient closely for $48 \mathrm{~h}$ was done when the hemoglobin level was between $7-9 \mathrm{~g} / \mathrm{dL}$ and this was performed in $100 \%$ of the cases.

- Repeat $\mathrm{Hb} \%$ next day after transfusion was done in $100 \%$ of the cases. 
Citation: El-Aty AMA, El-Deeb SAEF, Embaby MM (2017) An Audit on Management of G6PD Deficiency Acute Hemolytic Crisis. J Blood Lymph 7: 186. doi: $10.4172 / 2165-7831.1000186$

Page 4 of 5

\begin{tabular}{|c|c|c|}
\hline Items & Unit's protocol & Chick list \\
\hline \multirow{12}{*}{ Diagnosis } & 1. History & $\sqrt{ }$ \\
\hline & Fever, pallor & $\sqrt{ }$ \\
\hline & Dark urine & $\sqrt{ }$ \\
\hline & Stools normal & \\
\hline & First attack or recurrent & $\sqrt{ }$ \\
\hline & Any infection & $\sqrt{ }$ \\
\hline & 2. o/E & $\sqrt{ }$ \\
\hline & Pallor & $\sqrt{ }$ \\
\hline & Jaundice & $\sqrt{ }$ \\
\hline & Rash & $\sqrt{ }$ \\
\hline & Liver not enlarged & $\sqrt{ }$ \\
\hline & Spleen not enlarged & $\sqrt{ }$ \\
\hline \multirow{8}{*}{ Investigations } & 1.CBC with reticulocyte count & $100 \%$ \\
\hline & 2. Urine dipsticks & $80 \%$ \\
\hline & Bilirubin & \\
\hline & Urobilinogen & \\
\hline & blood & \\
\hline & 3. Blood urea and creatinine & $100 \%$ \\
\hline & 4. Total bilirubin:direct and indirect & $54 \%$ \\
\hline & 5. Blood group and cross matching & $100 \%$ \\
\hline \multirow{9}{*}{ Treatment } & I) Immediate & \\
\hline & a. Immediate stoppage of the offending drugs. & $100 \%$ \\
\hline & $\begin{array}{l}\text { b. If the hemoglobin level is below } 7 \mathrm{~g} / \mathrm{dl} \text { proceed } \\
\text { with blood transfusion: packed RBCs } 10 \mathrm{ml} / \mathrm{kg} \text { only. }\end{array}$ & $10 \%$ \\
\hline & + maintenance fluid with packed RBCs transfusion. & $6 \%$ \\
\hline & + sodium bicarbonate $1 \mathrm{ml} / \mathrm{kg}$ with $\mathrm{RBCs}$ and fluids. & $84 \%$ \\
\hline & $\begin{array}{l}\text { c. If the hemoglobin level is between } 7-9 \mathrm{~g} / \mathrm{dl} \\
\text { observe th patient closely for } 48 \text { hours. }\end{array}$ & $100 \%$ \\
\hline & $\begin{array}{l}\text { II) Repeat } \mathrm{Hb} \% \text { next day after packed RBCs } \\
\text { transfusion. }\end{array}$ & $100 \%$ \\
\hline & III) Give the patient the avoidance List. & $100 \%$ \\
\hline & $\begin{array}{l}\text { IV) Follow up after } 4 \text { weeks for estimation of } \\
\text { G6PD enzyme level in the outpatient department. }\end{array}$ & $100 \%$ \\
\hline
\end{tabular}

Table 1: Practicability of sticking to the unit's protocol.

- Giving the patients the avoidance list was done in $100 \%$ of the cases.

- Follow up the patients after 4 weeks for estimation of G6PD enzyme level in the outpatient department was done in $100 \%$ of the cases.

Table 2 shows a comparison between Unit's protocol and European Guidelines. Although our unit's protocol is similar to European guideline as a whole, yet under item of treatment (immediate) we were similar in $\mathrm{A}$ and $\mathrm{B}$ in the immediate treatment that is to say immediate stoppage of the offending drugs and $B$ the indication of blood transfusion+fluids+sodium bicarbonate if the hemoglobin level was below $7 \mathrm{~g} / \mathrm{dL}$. The use of sodium bicarbonate in the treatment of acute hemolytic crisis (as present in our unit's protocol) is logical in order to avoid acute renal tubular acidosis secondary to precipitation of denature hemoglobin particles blocking the renal tubules in order to avoid acute renal failure. We differ from the European guidelines because it was stated in their guidelines: if the hemoglobin level was $9 \mathrm{~g} / \mathrm{dL}$ and there was evidence of persistent brisk hemolysis i.e., with hemoglobinuria, immediate blood transfusion is also indicate. This shows the importance of doing regular dipsticks in all cases to detect hemoglobinuria as this will indicate immediate blood transfusion even if the hemoglobin level is $9 \mathrm{~g} / \mathrm{dL}$ or more. This is because hemoglobinuria indicates evidence of persistent brisk hemolysis. It is worthy while observing that urine dipsticks were done in only $80 \%$ of

\begin{tabular}{|c|c|c|}
\hline Items & Unit's protocol & European Guidelines \\
\hline \multirow{12}{*}{ Diagnosis } & 1. History & \\
\hline & Fever, pallor & $\sqrt{ }$ \\
\hline & Dark urine & $\sqrt{ }$ \\
\hline & Stools normal & $\sqrt{ }$ \\
\hline & First attack or recurrent & $\sqrt{ }$ \\
\hline & Any infection & \\
\hline & 2. o/E & $\sqrt{ }$ \\
\hline & Pallor & $\sqrt{ }$ \\
\hline & Jaundice & $\sqrt{ }$ \\
\hline & Rash & $\sqrt{ }$ \\
\hline & Liver not enlarged & $\sqrt{ }$ \\
\hline & Spleen not enlarged & \\
\hline \multirow{8}{*}{ Investigations } & 1. CBC with reticulocyte count & $\sqrt{ }$ \\
\hline & 2. Urine dipsticks & $\sqrt{ }$ \\
\hline & Bilirubin & $\sqrt{ }$ \\
\hline & Urobilinogen & $\sqrt{ }$ \\
\hline & Blood & $\sqrt{ }$ \\
\hline & 3. Blood urea and creatinine & $\sqrt{ }$ \\
\hline & 4. Total bilirubin:direct and indirect & $\sqrt{ }$ \\
\hline & 5. Blood group and cross matching & $\sqrt{ }$ \\
\hline \multirow{9}{*}{ Treatment } & I) Immediate & I) Immediate \\
\hline & $\begin{array}{l}\text { a. Immediate stoppage of the } \\
\text { offending drugs }\end{array}$ & $a-\sqrt{ }$ \\
\hline & $\begin{array}{l}\mathrm{b} \text {. If the hemoglobin level is } \\
\text { below } 7 \mathrm{~g} / \mathrm{dl} \text { proceed with blood } \\
\text { transfusion: packed RBCs } 10 \mathrm{ml} / \\
\mathrm{kg}+\text { maintenance fluid + sodium } \\
\text { bicarbonate } 1 \mathrm{ml} / \mathrm{kg}\end{array}$ & $b-\sqrt{ }$ \\
\hline & C1 & $\begin{array}{l}\text { c1. If the hemoglobin level } 9 \\
\mathrm{~g} / \mathrm{dl} \text { and there is evidence of } \\
\text { persistent brisk hemolysis } \\
\text { i.e with (hemoglobinuria), } \\
\text { immediate blood } \\
\text { transfusion is also indicated }\end{array}$ \\
\hline & $\begin{array}{l}\text { C2. if the hemoglobin level is } \\
\text { between } 7-9 \mathrm{~g} / \mathrm{dL} \text { observe the } \\
\text { patient closely for } 48 \text { hours }\end{array}$ & $c 2-\sqrt{ }$ \\
\hline & $\begin{array}{l}\text { II) Repeat } \mathrm{Hb} \% \text { next day after } \\
\text { packed RBCs transfusion }\end{array}$ & II- $\sqrt{ }$ \\
\hline & $\begin{array}{l}\text { III) Give the patient the avoidance } \\
\text { List * }\end{array}$ & III- $\sqrt{ }$ \\
\hline & $\begin{array}{l}\text { IV) Follow up after } 4 \text { weeks for } \\
\text { estimation of G6PD enzyme level in } \\
\text { the outpatient department }\end{array}$ & IV- $\sqrt{ }$ \\
\hline & $\begin{array}{l}\text { Treatment of infection if present and } \\
\text { was the precipitating factor }\end{array}$ & $\sqrt{ }$ \\
\hline
\end{tabular}

Table 2: A comparison between Unit's protocol and European Guidelines.

our cases. Detection of hemoglobinuria by urine dipsticks is important. In fact, the presence of hemoglobinuria in spite of the presence of a level of hemoglobin of $9 \mathrm{~g} / \mathrm{dL}$ may indicate immediate blood transfusion of packed RBCs because hemoglobinuria may indicate persistent brisk hemolysis, which if left will cause blockage of renal tubules leading to acute renal failure [9-15].

\section{Recommendations}

The use of bicarbonate in the treatment of acute hemolytic crisis should be continued. The importance of doing regular urine dipsticks in all cases of acute hemolytic crisis in order to detect hemoglobinuria must be emphasized as this will indicate immediate blood transfusion even if hemoglobin level is $9 \mathrm{~g} / \mathrm{dl}$ or more.

\section{References}

1. Bao B, Ting HJ, Hsu JW, Lee YF (2008) Protective role of 1a, 25-dihydroxyvitamin 
Citation: El-Aty AMA, El-Deeb SAEF, Embaby MM (2017) An Audit on Management of G6PD Deficiency Acute Hemolytic Crisis. J Blood Lymph 7: 186. doi: 10.4172/2165-7831.1000186

Page 5 of 5

D3 against oxidative stress in nonmalignant human prostate epithelial cells. Int J Cancer 122: 2699-2706.

2. Bautista J (2014) Epigenetic therapy reprograms hereditary disease. Blood pp: 1241.

3. DeBaun M, Frei-Jones M, Vichinsky E (2016) Nelson textbook of pediatrics (20 $0^{\text {th }}$ edn.), Hemoglobinopathies, pp: 2336-2353.

4. Francis R, Jhang J, Pham HP, Hod EA, Zimring JC, et al. (2013) Glucose6-phosphate dehydrogenase deficiency in transfusion medicine: the unknown risks. Vox Sanguinis 105: 271-282.

5. Glader B (2014) Hereditary hemolytic anemia's due to red blood cell enzyme disorders. In: Wintrobe's Clinical Hematology, (13th edn.), 28: 1683-1727.

6. Lee SW, Lai NM, Chaiyakunapruk N, Chong DW (2016) Adverse effects of herbal or dietary supplements in G6PD deficiency: A systematic review. $\mathrm{Br} J$ Clin Pharmacol 83: 172-179.

7. Jamshidzadeh A, Mehrabadi A (2010) Protective Effect of Quercetin on Oxidative Stress in Glucose-6-Phosphate Dehydrogenase-Deficient Erythrocytes in Vitro. Iranian Journal of Pharmaceutical Research 9: 169-175.

8. Luzzatto L, Seneca E (2014) G6PD deficiency: a classic example of pharmacogenetics with on-going clinical implications. British Journal of Haematology 164:469-480.
9. Luzzatto L (2015) Harrison's principles of internal medicine (edn19) In Hemolytic Anemias and Anemia Due to Acute Blood Loss, pp: 649:661.

10. Makarona K, Caputo VS, Costa JR, Liu B, O'Connor D, et al. (2014) Transcriptional and epigenetic basis for restoration of G6PD enzymatic activity in human G6PD-deficient cells. Blood 124: 134-141.

11. Rees D, Kelsey H, Richar J (1993) Acute haemolysis induced by high dose ascorbic acid in glucose-6-phosphate dehydrogenase deficienc. BMJ 306: 841-842.

12. Schuurman M, van Waardenburg D, Da Costa J, Niemarkt H, Leroy P (2009) Severe hemolysis and methemoglobinemia following fava beans ingestion in glucose-6-phosphatase dehydrogenase deficiency: case report and literature review. Eur J Pediatr 168: 779-782.

13. Segal G (2016) Nelson textbook of pediatrics (20 edn.), Definitions and Classification of Hemolytic Anemias, pp: 2327-2329.

14. Shan F, Yang R, Ji T, Jiao F (2016) Vitamin C Inhibits Aggravated Eryptosis by Hydrogen Peroxide in Glucose-6- Phosphated Dehydrogenase Deficiency. Cell Physiol Biochem 39: 1453-1462.

15. Tu h, Li H, Wang $Y$, Niyyati M, Wang $Y$, et al. (2015) Low Red Blood Cell Vitamin C Concentrations Induce Red Blood Cell Fragility: A Link to Diabetes via Glucose, Glucose Transporters, and Dehydroascorbic Acid. EBioMedicine 2: $1735-1750$. 